\title{
A Study on the Cultivation of Writing Ability of English Majors in Application-Oriented Colleges in China
}

\author{
Juan LIU \\ Wuchang Shouyi University, Wuhan, Hubei, China
}

\begin{abstract}
Keywords: English Majors; Writing Ability; Application-Oriented Colleges.
\end{abstract}
\begin{abstract}
Under the background of educational reform in higher education in China, more and more emphasis has been focused on learners' output; therefore, English writing, as the most fundamental combination of language input and output, has gained great attention in the process of cultivating of English majors' language proficiency in application-oriented colleges which prioritize learners' qualified output. Based on classroom observation and analysis of learners' writings, this paper aims at analyzing problems in the instruction of English writing, and constructive as well as feasible solutions are proposed to help English majors to develop critical writing ability.
\end{abstract}

\section{Introduction}

With the popularity of new media, English as an international language serves as a channel for learners to update their knowledge of the world and to share their understandings with others. Furthermore, in application-oriented colleges, English majors are encouraged to strengthen their connection with western culture through communication in various forms; therefore, English writing has become one of the effective ways to comprehensively evaluate learners' language proficiency, because in terms of language assessment, writing has gained more and more attention due to the complicated writing process with learners' thinking patterns involved. Based on the achievements of previous educational reforms in China, the instruction of English writing for English majors has been greatly improved, which can be seen in a higher level of learners' willingness of writing, fluency of language and complexity of contents. However, many problems in English majors' writing are so interrelated that effective solutions are anticipated to further improve English majors' writing.

\section{Significance of Writing Ability for English Majors}

Among the basic skills, listening and reading are vital ways for English majors to gain input, while speaking and writing are essential channels to assess learners' output. In addition, compared with speaking which has been regarded as the most important skill for English majors to achieve effective communication, writing ability has been widely accepted as a key element of the evaluation of learners' academic achievements; however, the significance of writing ability has not gained the equal emphasis.

According to the new standard of assessment model, English majors should master language skills and other core abilities ranging from humanity and discipline qualities to cooperation awareness and spirit. Among these standards, writing ability is indispensable for certain qualities, such as communication and expression, analysis of and solution to complicated problems, as well as critical thinking and innovation and so on.

Along with the development and improvement of language teaching approach and practice, the ultimate goals of cultivation of English talents in application-oriented colleges are closely related with social demands; therefore, the curriculum system and course designs have been changed correspondingly. In application-oriented colleges, the focus of instruction for English majors has been shifted from theoretical knowledge to practical skills. In terms of English writing, more attention has been focused on the writing process rather than the writing production. For English majors, the nature of writing is a display of their gains from various courses. Besides language skills, writing also reflects learners' thinking and creation characteristics and potentials. 
To sum up, through various ways of input, writing is to integrate learners' input to facilitate and demonstrate the development of English majors' language proficiency and core abilities in the form of impressive essays.

\section{Problems of Classroom Instruction of English Writing}

In China, classroom instruction is the most widely accepted way to teach learners English, with no exception to English majors. Although great improvement has been achieved with the implementation of advanced technologies, classroom instruction of English writing in applicationoriented colleges still face great challenges due to the following problems.

\subsection{Learners' motivation}

As one of the key internal factors, learning motivation plays a critical role in deciding the quality of learners' output. Compared with non-English majors, English majors are higher motivated when they try to complete writing tasks. However, their motivation is compromised by the high standard of various assessments and the complicated process and tasks of writing [1].

For English majors in application-oriented colleges, listening and speaking occupy most of their attention in and out of classroom instruction because these two skills are in accordance with social demands for English talents. On the contrary, according to the results of surveys and observations, writing is not frequently practiced due to English majors' negative attitude to it, thus when they are required to be excellent at academic writing as well as practical writing tasks, they always feel greatly challenged. Consequently, they are not fully active in the instruction of English writing mainly because of lack of motivation in the whole writing process.

\subsection{Teaching materials}

There are different types of writing textbooks and English articles that can be used as teaching materials in classroom instruction, but teachers still find it challenging to select appropriate teaching materials for learners due to the gap between teaching aim and learners' needs, which can hardly be satisfied in the context of the mixture of diversified learning styles and language levels [2,3]. Application-oriented colleges make great efforts to maintain a balance in cultivating English majors' academic and practical English abilities, but the teaching materials used in classroom instruction cannot guarantee the accomplishment of this goal. Moreover, writing textbooks are limited in terms of the updating of contents and concepts, which are key elements in improving English majors' writing ability.

\subsection{Teaching method}

Teaching method is essential for classroom instruction because it involves both the teaching and learning process. With the popularity of communicative, interactive and task-based language teaching approaches, learners have become the focus of teaching and learning. Based on this shift, instruction of writing also tends to be more interactive. However, this interactive teaching is mainly about the teaching of theoretical writing skills rather than the process of writing and feedback. Teaching method used in writing instruction should not just focus on the input of knowledge; instead, it should focus on the output of learners. As mentioned above, application-oriented colleges lay more emphasis on the output of learners, but the teaching method is not appropriately or efficiently practiced.

\subsection{Feedback on writing}

Writing is not only a product but also a process, and feedback is the dominating factor in the process to decide the final output of learners' writing. In the ideal writing instruction design, different types of feedback are adopted, while learners prefer teacher feedback to peer feedback [4]. However, the reality is that adequate and effective teacher feedback cannot be guaranteed because of too many learners in one classroom.

In real instruction, many teachers advocate peer feedback to encourage learners to cooperatively 
polish the language and improve the contents of learners' writing, but the effect is not satisfying due to learners' language proficiency and learning styles. Online feedback is another to help learners to get more feedback on their writing, but it is a single-direction method which lacks of interaction between readers and writers. Therefore, there is a dilemma in terms of feedback in writing instruction for English majors in colleges in China.

\section{Effective Solutions to the Problems}

Problems in writing instruction for English majors in application-oriented colleges are not confined to the ones mentioned above. As a teacher of English writing, the author proposes some solutions in order to contribute some constructive suggestions to enhancing the efficiency and effects of writing instruction.

\subsection{Free writing to motive learners}

The author encourages English majors, especially freshmen and sophomores, to write journals to record their life and thoughts, and comments or responses on heatedly discussed issues are praised. After two rounds of a two-year free writing, the author finds that most English majors in her classes become more active in writing instruction because they have mastered the theoretical knowledge related to writing in the frequent practice of free writing, which frees their minds and their creative use of language. Free writing can also be used to supplement writing tasks in and out of classroom instruction to provide learners with the opportunities to further explain and explore their understanding of certain topics. In other words, free writing can effectively motivate learners to develop their language and cognitive abilities.

In application-oriented colleges, English majors' language proficiency still needs to be enhanced, and they lack of confidence and perseverance to continually practice their writing; therefore, free writing gives them a chance to foster a habit of recording their life. More importantly, the writing process imposes less pressure on them, and individualized feedback becomes possible.

\subsection{Extensive reading to provide diversified writing materials}

Reading-based writing is a common practice in writing instruction for English majors, but reading materials are often chosen and analyzed by teachers in order to better present the related writing skills. This practice does not trigger learners' interests in reading or appreciating the given materials; moreover, it may make the reading-based writing more challenging by ignoring learners' reading ability [5]. The purpose of classroom instruction of writing is not about imitating the samples in textbooks but to help learners to generate their own writing ability.

Application-oriented colleges are more innovative in educational reform, so a more fruitful way can be carried out to change the existed practice of reading-based writing. Teachers can ask learners to read extensively to select reading-based materials for collaborative learning, which can supplement and substitute some writing samples in writing textbooks. In this way, learners are involved in the process of writing instruction by exercising their ability to appreciate different writings in order to construct their own understandings of English writing.

\subsection{Output-oriented writing instruction to involve learners}

Since writing is one essential form of output, the classroom instruction should be centered on how to improve the willingness of writing and the quality of output. According to the Production-Oriented Approach proposed by Wen Qiu-fang, writing instruction should be started by assigning writing tasks for learners in order to be familiar with learners' needs and problems in writing, and a gap between the known information and the new information is created to attract learners' attention to focus on the aspects they really need to improve; then learners polish and revise their drafts based on the skills they have mastered, which is an effective way to combine input and output [6]. This output-oriented writing instruction fits the framework of cultivation of English majors in application-oriented colleges by highlighting learners' abilities to analyze and solve problems as well as enhancing their 
awareness of cooperation, communication and expression.

\subsection{Collaborative feedback to present deepened understanding}

Collaborative feedback refers to the combination of teacher feedback and peer feedback, which aims to give learners' more feedback on their writings from different angles. Previous researches have indicated that teacher feedback is more reliable than peer feedback, so collaborative feedback is a feasible way to prioritize teacher feedback and integrate peer feedback, which can provide reliable feedback and different perspectives of learners' writings [7,8]. For English majors, collaborative feedback is beneficial for them because it offers various insights into their writings and offers them the opportunity to make final decisions to select the most valuable suggestions to adopt in their revised versions. This process goes beyond the writing itself by establishing a bridge between readers and writers to gain deepened understanding of their writings and to communicate more effectively through detailed exchanges of ideas. The whole process is output-intrigued, being in line with the cultivation aim of application-oriented colleges.

\section{Conclusion}

Under the background of educational reform in application-oriented colleges, output has become the goal of pursuits of teachers and learners. As a typical output form, writing ability naturally becomes the emphasis of classroom instruction for English majors who are supposed to be qualified in both academic and practical writing to meet diversified social demands. For application-oriented colleges in China, they cultivate their English talents according to social needs and demands, so they pay special attention to the quality of output of their talents. However, the cultivation of English majors' writing ability is a long-term goal due to the nature of writing as both a product and a process which is characterized by cognitive development.

This paper summarizes the significance of writing for English majors, analyzes the main problems in current writing instructions, and proposes some feasible solutions to the mentioned problems. Based on the author's teaching practice of writing and learners' achievements, writing motivation should be triggered by introducing free writing, extensive reading and appreciation should be encouraged, production-oriented writing should be integrated and practiced, and collaborative feedback from teachers and learners should be adopted to guarantee learners' improvement in writing.

\section{Acknowledgement}

This paper is supported by a university-sponsored project approved in 2018 in Wuchang Shouyi University. Project NO.: $2018 Z 07$.

\section{References}

[1] Z., Dörnyei, Researching Complex Dynamic Systems: "Retrodictive Qualitative Modeling" in the Language Classroom [J]. Language Teaching, 2014, 47 (1) 80-91.

[2] N., Profozic, The Effectiveness of Corrective Feedback and the Role of Individual Differences in Language Learning [M]. Peter Lang, Bern, 2013.

[3] M., Long, Problems in SLA [M]. Lawrence Erlbaum, Mahwah, N.J., 2007.

[4] R., Ellis, A Framework for Investigating Oral and Written Corrective Feedback [J]. Studies in Second Language Acquisition, 2010, 32 (2) 335-349.

[5] X., Zhang, Reading-Writing Integrated Tasks, Comprehensive Corrective Feedback, and EFL Writing Development [J]. Language Teaching Research, 2017, 21 (2) 217-240. (in Chinese)

[6] Wen, Qiu-fang, Teacher-Student Collaborative Assessment: A New Assessment Form based on Production-Oriented Approach [J]. Foreign Language World, 2016, 176 (5) 37-43. (in Chinese) 
[7] T., Nishino, D., Atkinson, Second Language Writing as Sociocognitive Alignment [J]. Journal of Second Language Writing, 2015, 27 (1) 37-54.

[8] Y., Yilmaz, Relative Effects of Explicit Corrective Feedback: The Role of Working Memory Capacity and Language Analytic Ability [J]. Applied Linguistics, 2013 (34) 344-368. 